CITE AS Frankl, A., Stal, C., Abraha, A., Nyssen, J., Rieke-Zapp, D., De Wulf, A., Poesen, J., 2015. Detailed recording of gully morphology in 3D through image-based modelling. Catena 127, 92-101.

\title{
1 Detailed recording of gully morphology in 3D through image-based modelling
}

3 Amaury Frank1 ${ }^{1, a, *}$, Cornelis Stal ${ }^{1, a}$, Amanuel Abraha ${ }^{2}$, Jan Nyssen ${ }^{1}$, Dirk Rieke-Zapp ${ }^{3}$, Alain De

4 Wulf $^{1}$, Jean Poesen ${ }^{4}$

$5 \quad{ }^{a}$ Both authors contributed equally to this work.

$6{ }^{1}$ Department of Geography, Ghent University, Belgium.

$7 \quad{ }^{2}$ Institute of Climate and Society, Mekelle University, Ethiopia.

$8{ }^{3}$ Breuckmann GmbH, D-88709 Meersburg, Germany.

$9{ }^{4}$ Division of Geography, Department of Earth and Environmental Sciences, KU Leuven, 10 Belgium.

$12 *$ Corresponding author: Tel.: +32 92644701; fax: +32 92644985; e-mail address: 13 amaury.frankl@ugent.be (A. Frankl)

15 Abstract

16 The ability to understand gully erosion development is closely related to our ability to quantify

17 the morphology of gullies. At present, various technologies are at hand to collect data at 18 increasing levels of detail. However, many of the developed technologies are time-consuming, 19 difficult to apply or expensive. As an alternative, image-based modelling offers a cost-efficient, 20 flexible and rapid method to quantify gully morphology from photographs taken in the field. In 21 this study, the use of image-based modelling was tested and fine-tuned to quantify the 
CITE AS Frankl, A., Stal, C., Abraha, A., Nyssen, J., Rieke-Zapp, D., De Wulf, A., Poesen, J., 2015. Detailed recording of gully morphology in 3D through image-based modelling. Catena 127, 92-101.

22 morphology of four gully heads in contrasting biophysical environments prone to gully erosion:

23 two bank gullies in Central Belgium and two permanent gullies in Northern Ethiopia. Ground 24 photographs $(\mathrm{n}=88-235)$ were taken with a reflex Canon EOS 450D camera having a $20 \mathrm{~mm}$

25 wide-angle lens with a fixed focal length. The data collection occurred during days of 30-100\% 26 cloud cover and after removing excessive vegetation in the gullies. Processing of the 27 photographs occurred in PhotoScan 1.0.2. software using the semi-automated Structure from 28 Motion-Multi View Stereo (SfM-MVS) workflow, and allowed to produce 3D Digital Elevation 29 Models with accuracies that range from millimetres to centimetres. In addition, for the same 30 surface, 2.5D models were created in ArcGIS. Gully morphological properties were derived and 31 include cross-sections, total volume and volume of undercut walls and soil pipe inlets. For the 32 volume calculation, OPTOCAT software was used. Cross-sections were also quantified by tape 33 meter measurements. When compared to 3D models, cross-sections quantified from tape meter 34 measurements and from 2.5D models underestimate the cross-sectional area by $<1-14 \%$ and 0 $352.5 \%$ respectively. Considering gully volume, $2.5 \mathrm{D}$ and $3 \mathrm{D}$ approximations show only small 36 differences, related to the volume of soil pipe inlets and undercutting areas. These differences, 37 however, highlight the erosive activity of the gullies, and are important to understand gully 38 dynamics in detail. Geomorphologically spoken, areas where undercutting or soil piping occurs 39 are among the most dynamic and reveal where important morphologic changes are about to occur. 40 The accuracies reported in this study are similar to those obtained in other studies that consider 41 surfaces of similar scales. In sum, image based modelling is a promising tool to study in detail 42 gully morphology in 3D, which is the closest approximation of the surface morphology. 
CITE AS Frankl, A., Stal, C., Abraha, A., Nyssen, J., Rieke-Zapp, D., De Wulf, A., Poesen, J., 2015. Detailed recording of gully morphology in 3D through image-based modelling. Catena 127, 92-101.

44 Keywords: PhotoScan; Digital Elevation Model (DEM); soil pipes; Structure from Motion-

45 Multi View Stereo (SfM-MVS); volume calculation.

\section{1. Introduction}

48 Detailed understanding of the causes and consequences of soil erosion is of paramount

49 importance whenever societies want to ensure their sustainability, especially facing global

50 climate change (Montanarella and Vargas, 2012). Thoughtless planning has frequently shown

51 that the delicate balance between the exploitation of natural resources and the resilience of the

52 environment can easily be violated. Deforestation, agricultural intensification, overgrazing,

53 urbanization and flow diversion by infrastructure construction are frequently mentioned as

54 causes of accelerated erosion by gullying and river channel degradation (Knighton, 1998;

55 Schumm, 2005). Typical for dryland environments is severe gully erosion and river channel

56 degradation related to the degradation of the vegetation cover and flow diversions, often in

57 combination with the occurrence of climatic shocks (Valentin et al., 2005). In subhumid and

58 humid environments, rapid gully development and river bed degradation also occurs when poor

59 land management is applied. Most striking in that regard is probably the incision of tropical soils

60 after the clearance of rain forests (e.g., Clarke and Walsh, 2006). In light of striving towards a

61 'land-degradation neutral' world, a Rio+20 conference target, rapid and detailed understanding of

62 local erosion processes is ever more crucial. This requires scientists to rapidly access precise data

63 on the development of erosion features, so that causal relations can be thoroughly understood. 
CITE AS Frankl, A., Stal, C., Abraha, A., Nyssen, J., Rieke-Zapp, D., De Wulf, A., Poesen, J., 2015. Detailed recording of gully morphology in 3D through image-based modelling. Catena 127, 92-101.

64 Methods for monitoring morphological changes of gullies and river channels are mostly based on 65 in-situ measuring techniques or quantifications from remote sensing products and their Digital 66 Elevation Model (DEM) derivates (Poesen et al., 2003). In situ measuring is often time 67 consuming and requires accurate measuring equipment, like a total station, highly accurate 68 Global Navigation Satellite System (GNSS) receivers, or laser profilometers (Castillo et al., 69 2012), which are not always at hand or are expensive to rent. Moreover, very dense 70 measurements of xyz-coordinates are usually required to fully grasp the morphological 71 developments in channel degradation or aggradation. This is only offered by the use of 72 Terrestrial Laser Scanning (TLS) (Perroy et al., 2012) or Airborne Laser Scanning (ALS) 73 (Heritage and Hetherington, 2007). The use of TLS is limited for the same reasons as for the 74 conventional topographic sensors. ALS often lacks the accuracy to precisely capture the 75 morphology of small channels (Perroy et al., 2010), and in terms of cost and feasibility, its use is 76 also limited for most monitoring projects. Other remote sensing products, such as aerial 77 photographs and satellite images, need to have a sufficiently high resolution to accurately 78 quantify volumes from their DEM products (Giménez et al., 2009). High resolution images 79 (having a resolution $<1 \mathrm{~m}$ ) are increasingly available at short time intervals. However, when 80 requiring stereoscopic views, acquiring the images is usually financially out of reach of most 81 projects. Collecting high resolution data is also done from a remotely controlled blimp from 82 which large-scale stereographic aerial photographs can be taken (Ries and Marzolff, 2003; 83 Marzolff and Poesen 2009). Similar data can be obtained from cameras which are mounted on 84 Unmanned Aerial Vehicles (UAVs). Given their low-cost and flexible nature, the latter are 
CITE AS Frankl, A., Stal, C., Abraha, A., Nyssen, J., Rieke-Zapp, D., De Wulf, A., Poesen, J., 2015. Detailed recording of gully morphology in 3D through image-based modelling. Catena 127, 92-101.

85 increasingly being used in geosciences applications (Corbane et al., 2008; Hendrickx et al., 2011;

86 Lucieer et al., 2013; Peter et al., 2014). Image-based modelling is a recent and promising 87 development in photogrammetry which allows to created textured models from a set of 88 conventional terrestrial or airborne photographs, taken from the same surface. The methodology 89 is based on semi-automated Structure from Motion and MultiView Stereo (SfM-MVS) 90 workflows (Seitz et al., 2006; Verhoeven et al., 2013; Javernick et al., 2014), which are 91 integrated in software such as PhotoScan (Agisoft). It is rapidly gaining interest of various 92 scientific disciplines which require to model objects or terrain features, often in combination 93 with UAV surveys. For example, image-based modelling was used to produce accurate models of 94 historical globes (Stal et al., 2012), buildings (Stal et al. 2011), gullies (Castillo et al., 2012; 95 Gómez-Gutiérrez et al., 2014; Kaiser et al., 2014), landforms (James and Robson, 2012) and 96 even specific landscapes (Verhoeven et al., 2012). However, most studies use image-based 97 modelling in a 2.5D environment, in which every xy-coordinate yields only one z-coordinate.

98 This is often related to the nature of recording from an airborne perspective (e.g., aerial 99 photography), from which vertical morphologies are (largely) hidden from the observation point 100 (Giménez et al., 2009; Marzolff and Poesen, 2009). For erosion studies, understanding in detail 101 the erosion dynamics and processes involved, however, requires to produce 3D models, in which 102 the actual 3D topography is approximated, including areas for which multiple z-coordinates exist 103 for unique xy-coordinates. This allows to model complex morphologies such as soil pipe inlets 104 and overhanging walls, which are key indicators of the erosivity of the gully headcut (Frankl et 105 al., 2012). 
CITE AS Frankl, A., Stal, C., Abraha, A., Nyssen, J., Rieke-Zapp, D., De Wulf, A., Poesen, J., 2015. Detailed recording of gully morphology in 3D through image-based modelling. Catena 127, 92-101.

106 Therefore, the objective of this study is to present the use of image-based modelling for the 107 production of detailed 3D models of gully heads from a ground-based approach. The method 108 allows better understanding of gully morphologies, required to understand processes involved, 109 and can be used to monitor changes at very high spatio-temporal scales.

\section{2. Material and methods}

\section{$112 \quad 2.1$ Selected sites}

113 The study areas represent two contrasting environments sensitive to gully erosion, i.e. the rolling 114 landscape of the European loess belt (Poesen and Govers, 1990) and the east African highlands 115 (Frankl et al., 2011, 2012; Fig. 1). Two bank gullies were selected in Bertem, located in the 116 Belgian loess belt (Bel1: $50.833^{\circ} \mathrm{N}, 4.630^{\circ} \mathrm{E}$ and Bel 2: $50.837^{\circ} \mathrm{N}, 4.621^{\circ} \mathrm{E}$; Fig. 2), where 117 elevations range between 20 and $110 \mathrm{~m}$ a.s.l. The selected gullies developed in sunken lane 118 banks, representing an important cause of soil losses in the region (Poesen et al. 1996). Gully 119 Bel2 was partially filled soon after data collection by a farmer in order to limit the loss of 120 agricultural land by the rapid expanding gully head.

121 The lithology consists of unconsolidated Cenozoïc marine sands covered by a loess layer with a 122 thickness varying between a few decimetres up to several meters (Vanwalleghem et al., 2005).

123 Typical soils for these deposits are Haplic Luvisols with a clay-illuviation horizon (Bt) at 35-45 $124 \mathrm{~cm}$ below the soil surface (Vanwalleghem et al., 2005). According to the Köppen-Geiger climate 125 classification, this area is characterized by a Cfb humid temperate climate with no dry season and 126 warm summers (Peel et al., 2007). Annual precipitation varies between 750 to $800 \mathrm{~mm}^{-1}$ 
CITE AS Frankl, A., Stal, C., Abraha, A., Nyssen, J., Rieke-Zapp, D., De Wulf, A., Poesen, J., 2015. Detailed recording of gully morphology in 3D through image-based modelling. Catena 127, 92-101.

127 (Alexandre et al., 1998). Another two gully heads were selected in Adi Kwolakol (near Hagere 128 Selam), located in the north Ethiopian highlands (Eth1: $13.655^{\circ} \mathrm{N}, 39.209^{\circ} \mathrm{E}$ and Eth2: $13.654^{\circ} \mathrm{N}$, $12939.210^{\circ} \mathrm{E}$; Fig. 2), where elevations range between 2000 and $4500 \mathrm{~m}$ a.s.l. Here, Mesozoïc 130 sandstones and limestones, and Cenozoïc basalts are exposed (Merla et al., 1979). Due to intense 131 geomorphological processes, Regosols, Cambisols and Leptosols dominate the soil catenas that 132 developed on the different lithologies (Nyssen et al., 2008). The climate is classified as hot 133 semiarid Bsh, with a prolonged dry season and a short monsoon-type rainy season (Peel et al., 134 2007). Annual precipitation shows a large inter-annual variability and is on average $550 \mathrm{~mm} \mathrm{y}^{-1}$ 135 (Jacob et al., 2013).
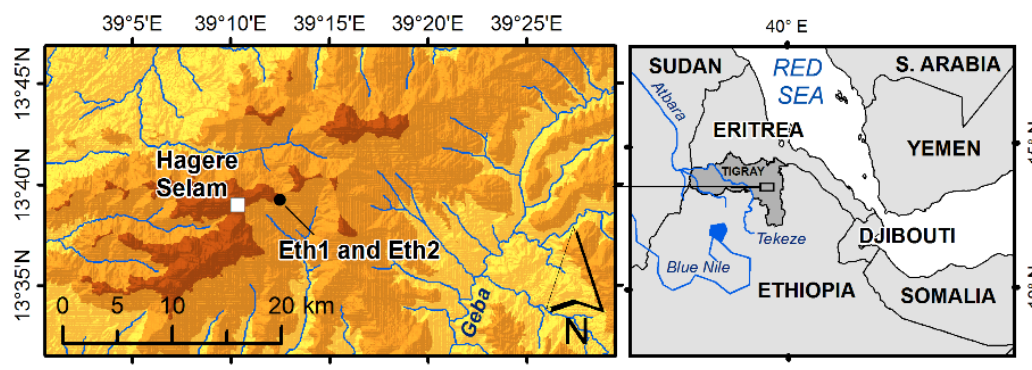

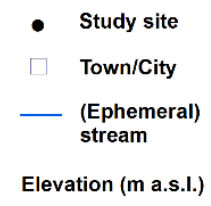

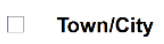

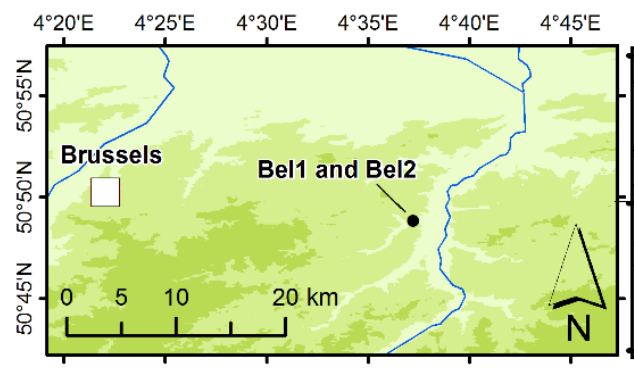
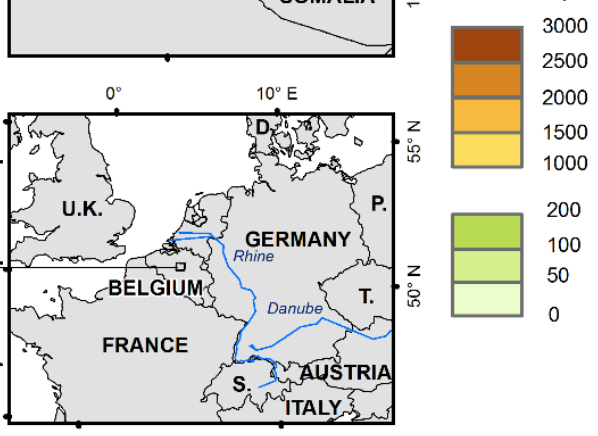

2500 2000

1500
1000

137 Figure 1: Location of study sites in Belgium and Ethiopia. 
CITE AS Frankl, A., Stal, C., Abraha, A., Nyssen, J., Rieke-Zapp, D., De Wulf, A., Poesen, J., 2015. Detailed recording of gully morphology in 3D through image-based modelling. Catena 127, 92-101.
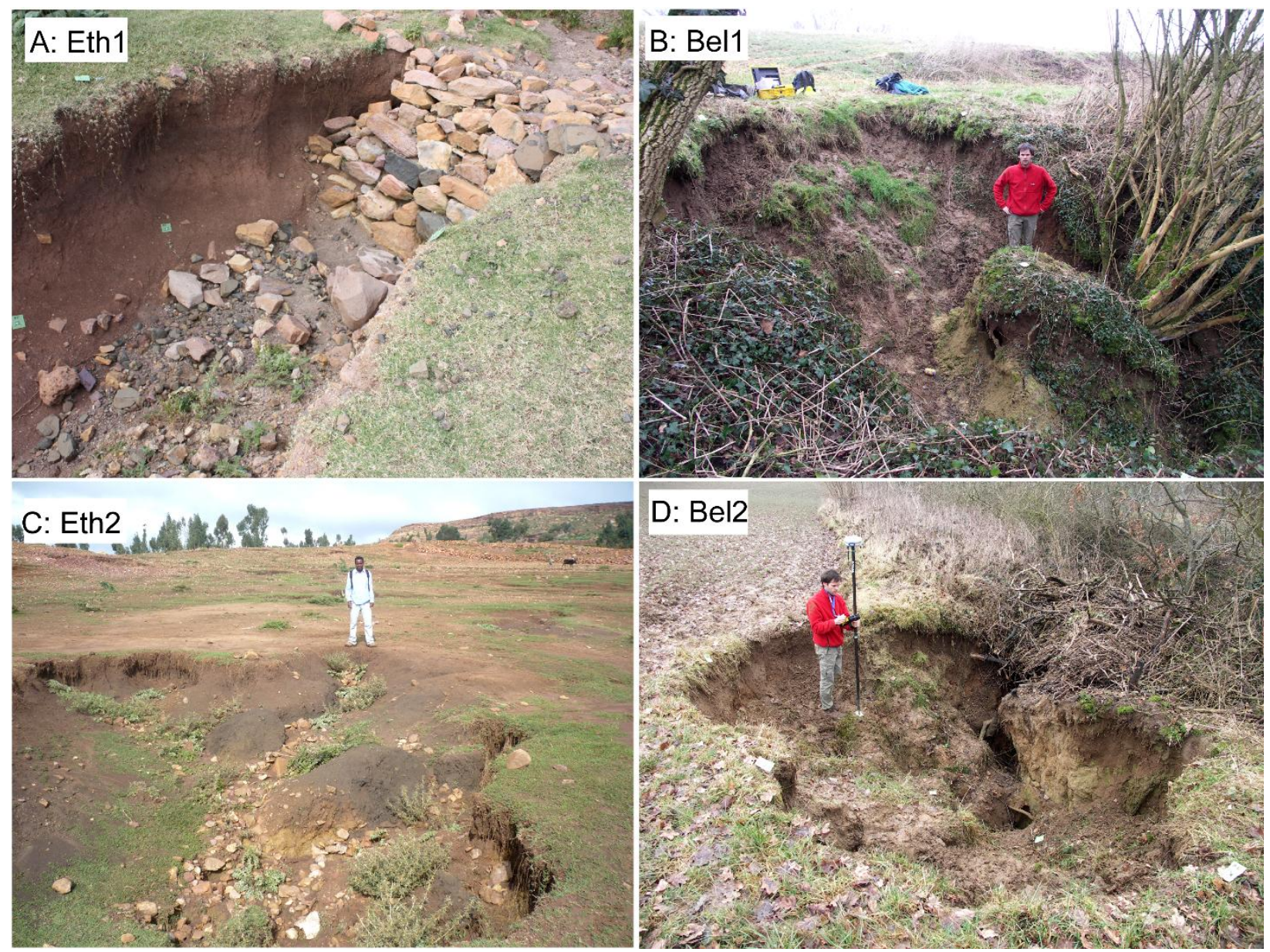

141 Figure 2: Selected gully heads in Ethiopia (A,C) and in Belgium (B,D) used for image-based 3D

142 modelling.

\subsection{Data collection}

145 Data collection occurred on February 21, 2013 in Belgium (gullies Bel1 and Bel2) and on June

146 12, 2013 in Ethiopia (gullies Eth1 and Eth2). Inside the gullies, where necessary, vegetation was

147 clipped near the soil surface. This was especially required for the gullies in Belgium where tall

148 grass grew on the gully walls and bottom, and some large shrubs overgrew the gullies. Markers 
CITE AS Frankl, A., Stal, C., Abraha, A., Nyssen, J., Rieke-Zapp, D., De Wulf, A., Poesen, J., 2015. Detailed recording of gully morphology in 3D through image-based modelling. Catena 127, 92-101.

149 were installed at the gully headcuts in order to indicate both Ground Control Points (GCPs) and 150 gully cross-sections. For each gully head, one or two cross-sections were defined by marking the 151 profile knick points along a vertical plane. Cross-sections top width, bottom width and maximum 152 depth (m) were quantified using a tape meter. As a high-accuracy Trimble R6 GNSS antenna 153 (using the Flemish Real Time Kinematic network, FLEPOS) was available for the measurements 154 in Belgium, 20 GCPs were recorded for gullies Bel1 and Bel2 (Fig. 2D), and 103 randomly 155 distributed measurements were done for an accuracy assessment. Planimetric and altimetric 156 accuracies of these measurements were between 3 and $6 \mathrm{~cm}$ (95\% or 2 standard deviations; 157 AGIV, 2008). For the measurements in Ethiopia, an accurate GNSS was not available, neither in 158 RTK, nor in differential mode. Therefore, a handheld Garmin Etrex GPS (2 m standard deviation) 159 was used to record one GCP for the gullies Eth1 and Eth2. For the scaling and referencing of 160 Eth1 and Eth2 (Section 2.3), the distance between two to three GCPs was measured in the field. 161 Moreover, the orientation between the GCP used for positioning the model and nearby GCPs was 162 measured by compass.

163 Photographic recording of the gully heads was done when there was no direct irradiance from 164 the sun in the gullies. The latter would produce cast shadows, causing large differences in 165 contrast between light and dark areas, making image matching in the image modelling (Section 166 2.3) less accurate or potentially impossible. Collecting photographs for the production of virtual 167 3D models was done with a reflex Canon EOS 450D camera, having a $20 \mathrm{~mm}$ wide-angle lens 168 and a fixed focal length (35 mm equivalent focal length is $28.6 \mathrm{~mm}$ ). No special camera settings 169 were required, only those that ensure sharp images having good contrast given the light 
CITE AS Frankl, A., Stal, C., Abraha, A., Nyssen, J., Rieke-Zapp, D., De Wulf, A., Poesen, J., 2015. Detailed recording of gully morphology in 3D through image-based modelling. Catena 127, 92-101.

170 conditions without the need of using the flash. Photographing the gully headcuts was done from

171 several viewpoints (located both outside and inside the gully), thus creating a large dataset of

172 overlapping photographs (Fig. 3). By recording from multiple viewpoints with approximately

173 parallel baselines, and by respecting a minimum overlap of $50 \%$ between subsequent

174 photographs, parallaxes needed for the 3D modelling were created. Gully Bel2 that was filled by 175 farmer operations was rephotographed in order to have both the incised and the filled situation 176 for that gully.

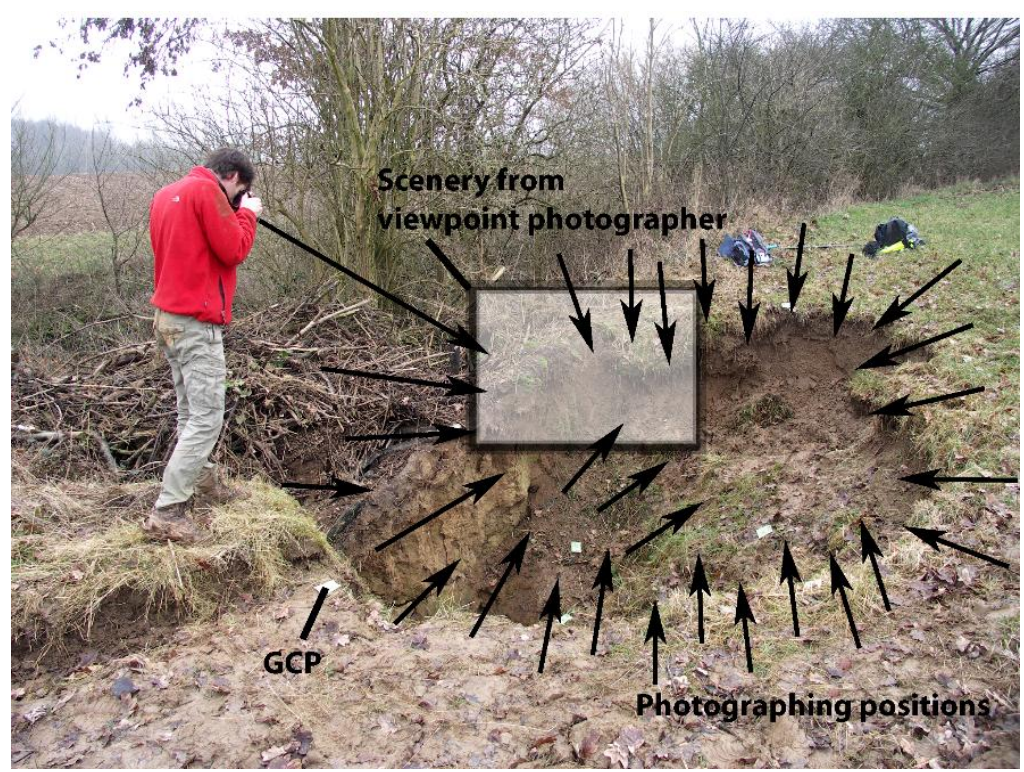

179 Figure 3: Data acquisition (at bank gully head Bel2) occurs by photographing the gully head 180 from multiple viewpoints (including from inside the gully), ensuring $50 \%$ overlap between 181 subsequent recordings. A fixed zoom is chosen in relation to the scenery covered from the 182 viewpoints. Arrows indicate direction of photographs taken. 
CITE AS Frankl, A., Stal, C., Abraha, A., Nyssen, J., Rieke-Zapp, D., De Wulf, A., Poesen, J., 2015. Detailed recording of gully morphology in 3D through image-based modelling. Catena 127, 92-101.

\subsection{Image-based 3D modelling and accuracy assessment}

185 Producing virtual 3D models from the photographs was based on a Structure from Motion 186 Multi-View Stereo (SfM-MVS) integrated workflow (Fig. 4). It is implemented in various 187 software, such as Blender, Microsoft PhotoSynth or PhotoScan (version 1.0.2., Agisoft), with the 188 latter being used here. The whole procedure runs automatically, only requiring the photographs 189 and their metadata from the EXIF image-files (like focal length, focal point and image size) as 190 inputs. If metric 3D models are required, the workflow will be semi-automatic, as GCPs need to 191 be identified manually. Furthermore, user-interference is required for quality control and for the 192 (optional) manual edition and fine-tuning of the models (delete peaks and troughs which result 193 from erroneous matching). The SfM-MVS methodology is very similar to conventional 194 photogammetry, with the main difference that instead of using one stereo couple, a large series of 195 photographs of the same scene is used. Basically, the SfM method allows to create a 3D 196 structure from multiple 2D images (i.e. terrestrial photographs). This included a feature point 197 detection and description, image matching (cfr., defining tie-points), image triangulation and 198 bundle adjustment (creation of a sparse 3D point cloud of image matching points based on the 199 projection of image pixels in 3D).

200 Referencing the 3D models into a coordinate system was done in a different way for the gully

201 heads in Belgium and those in Ethiopia. For the gullies Bel1 and Bel2 (and Bel2 $2_{\text {Filled }}$ ), 20 GCPs 202 (measured with Trimble R6 GNSS antenna) were used to scale and georeference the 3D models 203 into the UTM-WGS1984 coordinate system. For the gullies Eth1 and Eth2, the 3D models were 204 first scaled using the measured distance between two to three GCPs (Section 2.2). As these 
CITE AS Frankl, A., Stal, C., Abraha, A., Nyssen, J., Rieke-Zapp, D., De Wulf, A., Poesen, J., 2015. Detailed recording of gully morphology in 3D through image-based modelling. Catena 127, $92-101$.

205 measurements occurred with a tape meter, accurate at centimetre-level, the relative accuracy is 206 ought to be similar to the georeferencing of the Bel1 and Bel2 gullies. Positioning the gully 207 models Eth1 and Eth2 in the UTM-WGS 1984 coordinate system was done using one GCP 208 (measured with handheld GPS). Resolving the tilt in $\mathrm{X}, \mathrm{Y}$ and $\mathrm{Z}$ was done by considering the 209 orientation between the GCP used for positioning the model and nearby GCPs, and by 210 considering a vertical plane defined along the cross-sections.

211 Resolving the 3D geometry was done with the MVS method (in PhotoScan 1.0.2.), allowing 212 producing a dense estimate of the surface geometry in the form of a Triangulated Irregular 213 Network (TIN). This is based on the intersection of corresponding pixels projected from different 214 camera positions and orientations in 3D (Lourakis and Argyros, 2009). The triangulation of the 215 mesh occurred by connecting all points in the 3D model (Pfeifer, 2002). In order to quantify the 216 importance of soil piping and undercutting at the gully head, an additional 2.5D models from the 217 triangulated mesh was created in ArcGIS 10 (ESRI). 
CITE AS Frankl, A., Stal, C., Abraha, A., Nyssen, J., Rieke-Zapp, D., De Wulf, A., Poesen, J., 2015. Detailed recording of gully morphology in 3D through image-based modelling. Catena 127, 92-101.

\begin{tabular}{|c|c|c|c|c|}
\hline Norkflow & & & Processes & Product \\
\hline & 1) & Clearing vegetation in & the gully & \\
\hline 물 & 2) & Defining GCPs and gu & Ily cross-sections & \\
\hline $\begin{array}{ll}3 \\
0 \\
0\end{array}$ & 3) & GNSS measurements & of GCPs & ASCII-file with $x y z$ data \\
\hline & 4) & $\begin{array}{l}\text { Collecting terrestrial pr } \\
\text { (incl. metadata) }\end{array}$ & hotographs & JPG + RAW \\
\hline & 5) & Identifying GCPs on th & e terrestrial photographs & \\
\hline ट्ञ & 6) & Structure from Motion & $\begin{array}{l}\text { feature point detection/description } \\
\text { image matching } \\
\text { image triangulation } \\
\text { bundle adjustment }\end{array}$ & Sparse point cloud \\
\hline$\frac{1}{2}$ & 7) & Multi-View Stereo & $\begin{array}{l}\text { mesh triangulation } \\
\text { absolute orientation in UTM-WGS } 1984\end{array}$ & $\begin{array}{l}\text { Dense point cloud } \\
\text { (TIN surface) }\end{array}$ \\
\hline$\frac{0}{0}$ & 8) & Post-processing & $\begin{array}{l}\text { removing spikes, } \\
\text { holes, faces bordering the } \\
\text { area of interest }\end{array}$ & \\
\hline & 9) & $\begin{array}{l}\text { Texture Mapping by co } \\
\text { or by draping photogra }\end{array}$ & $\begin{array}{l}\text { lor coding mesh faces } \\
\text { aphs }\end{array}$ & \\
\hline & 10) & Creating a textured $3 D$ & model & WRL, OBJ, STL, ... \\
\hline
\end{tabular}

220 Figure 4: The major steps in image-based 3D modelling. The implementation of this scheme in 221 PhotoScan can be found on http://www.agisoft.ru/.

223 During the geometric 3D reconstruction, a single colour value, based on averaged colour values 224 of all corresponding pixels from different images, was assigned to each face in the mesh. A 225 detailed and photorealistic texture map was obtained by projecting photographs onto the mesh. 226 Full description of the SfM-MVS methodology and image-based 3D modelling can be found in 227 Robertson and Cipolla (2009), Seitz et al. (2006) and Remondino and El-Hakim (2006).

228 The overall accuracy of the models was assessed by comparing distances between GCP 229 measured in the field (not used in the DEM creation) with those computed from the 3D models. 
CITE AS Frankl, A., Stal, C., Abraha, A., Nyssen, J., Rieke-Zapp, D., De Wulf, A., Poesen, J., 2015. Detailed recording of gully morphology in 3D through image-based modelling. Catena 127, 92-101.

230 In addition, for the Bel1 and Bel2 models, the elevation of extra GNSS sample points were 231 compared to the elevation of the corresponding planimetric position in the 3D model. The 232 resulting RMSE in $\mathrm{z}$ allowed assessing the accuracy of the $3 \mathrm{D}$ models, in relation with the 233 accuracy of the GNSS measurements.

\subsection{Analysing gully morphology and volumes}

236 First, a visual analysis of the draped 3D models was performed. Second, cross-sections that were 237 measured in the field were compared to those derived from the 2.5D and 3D models. From field 238 measurements, cross-sectional area is typically described by the formula:

242 With $\mathrm{CSA}=$ cross-sectional area $\left(\mathrm{m}^{2}\right), \mathrm{TW}=$ top width $(\mathrm{m}), \mathrm{BW}=$ bottom width $(\mathrm{m})$ and $\mathrm{D}=$

243 maximum depth (m). Cross-sections from the 2.5D models were created with Spatial Analyst in 244 ArcGIS10. For the 3D models, Spark (Geomagic) was used.

245 For the calculation of $2.5 \mathrm{D}$ and $3 \mathrm{D}$ volumes, the models were imported in STL format into 246 OPTOCAT 2014 software (Breuckmann 2014 - http://www.breuckmann.com). Since volume 247 calculations require a closed mesh and the PhotoScan mesh output contained many flipped 248 triangles and holes, the OPTOCAT's hole fill module was used to improve the mesh. Afterwards 249 an inclined plane was fitted around the gully outline to determine the upper limit of the volume 250 calculation and to calculate $3 \mathrm{D}$ and $2.5 \mathrm{D}$ volumes. The $2.5 \mathrm{D}$ representation was calculated from 
CITE AS Frankl, A., Stal, C., Abraha, A., Nyssen, J., Rieke-Zapp, D., De Wulf, A., Poesen, J., 2015. Detailed recording of gully morphology in 3D through image-based modelling. Catena 127, 92-101.

251 the 3D data with OPTOCAT's analysis tools. The raster resolution was chosen to represent 10 $252 \mathrm{~mm}$ in reality, i.e. a regular X,Y- raster with sampling distance of $10 \mathrm{~mm}$. The $2.5 \mathrm{D}$ model could 253 be calculated representing the minimum, maximum or average projected height in the given $\mathrm{X}, \mathrm{Y}$ 254 cell. In this case the maximum height was chosen to calculate the difference between $3 \mathrm{D}$ and $2552.5 \mathrm{D}$ volumes. Calculation of the volume under the reference plane for the 3D and 2.5D surfaces 256 was performed using OPTOCAT's calculate volume function.

\section{Results}

259 The image-based 3D models of the gullies were produced based on 88 up to 235 photographs 260 (Table 1). The Ground Sampling Distance (GSD), which is a measure for the model-resolution in 261 xyz, varied between $0.45 \mathrm{~mm}$ and $0.72 \mathrm{~mm}$. The relative accuracy of the models was expressed 262 by comparing distances between GCPs measured in the field (ranging from ca. 0.5 to $3 \mathrm{~m}$ ), to 263 those computed from the models. For gullies Bel1 and Bel2 and Eth1, this error was very small, 264 at millimeter to centimeter level (Table 1). This coincides to a weighted average error smaller 265 than 1\%. For gully Eth2, the accuracy error of the model was one order of magnitude larger, with 266 the distance error being $0.1 \mathrm{~m}$ and the weighted average $9 \%$. The latter can however largely be 267 explained by an outlier in the dataset (possible a spike in the model), as can also be derived from 268 the much smaller standard deviation. As GNSS measurements were available for Bel1 and Bel2, 269 an $\mathrm{RMSE}_{\mathrm{z}}$ was computed on a large set of points. The resulting errors were $0.148 \mathrm{~m}$ for Bel1 and $270 \quad 0.155 \mathrm{~m}$ for Bel2, which is similar to the 0.05-0.10 m accuracy level of the GNSS measurements

271 (Table 1). Note that the rather low accuracy of the GNSS sensor was caused by a limited number 
CITE AS Frankl, A., Stal, C., Abraha, A., Nyssen, J., Rieke-Zapp, D., De Wulf, A., Poesen, J., 2015. Detailed recording of gully morphology in 3D through image-based modelling. Catena 127, 92-101.

272 of satellite signals received by the antenna while measuring under/in the proximity of trees.

273

Table 1: 3D Models characteristics and accuracies.

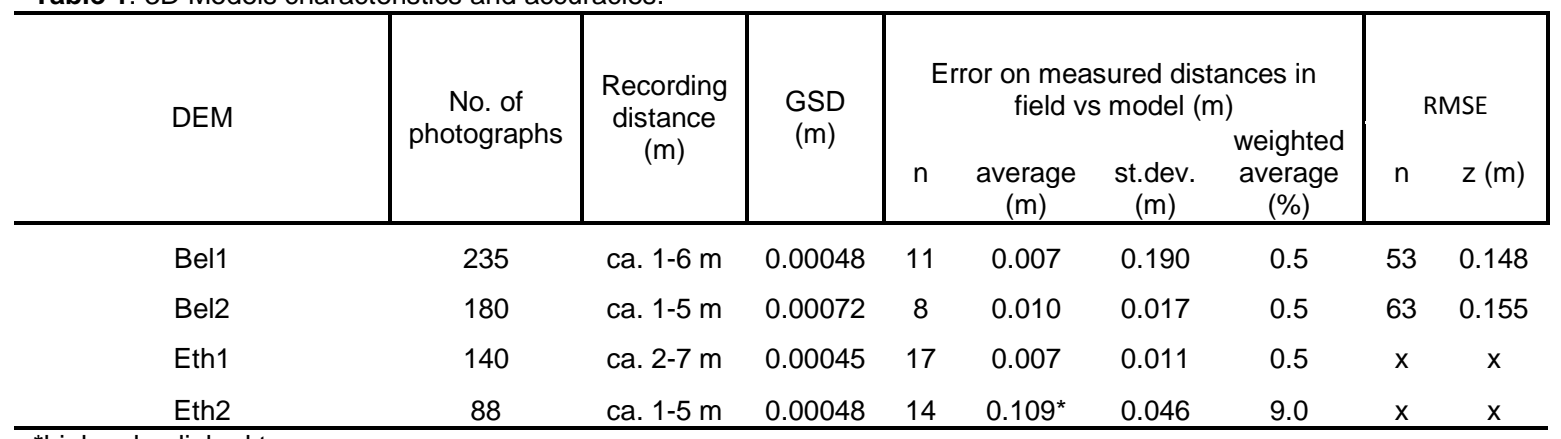

*high value linked to an

274

outlier

275 Fig. 5A-D shows both the 2.5D and the image-based 3D models of gully Bel1 and Eth1. The

276 2.5D models show the gully morphology from a vertical perspective, in a conventional

277 representation of a shaded colour-coded elevation range. Visual analysis of these models reveal

278 the details of the gully morphology, including vertical walls and large soil clods and boulders on

279 the floor of gully Eth1, and for Bel1, a closed depression $(<0.5 \mathrm{~m})$ on the gully floor. 3D

280 visualizations of these models would not give us more information on the gully morphology, as

281 each xy-coordinate has only one z-coordinate. Similar views are given for the 3D photomodels,

282 that were colour coded by using the average pixel colour values of photographs used to create the

283 surface. As can be observed in Fig. 7, 3D visualisations do provide additional information, as

284 overhanging walls and pipe inlets become visible. This is related to the possibility to assign

285 multiple z-coordinates to single xy-coordinates in the 3D models. 
CITE AS Frankl, A., Stal, C., Abraha, A., Nyssen, J., Rieke-Zapp, D., De Wulf, A., Poesen, J., 2015. Detailed recording of gully morphology in 3D through image-based modelling. Catena 127, 92-101.
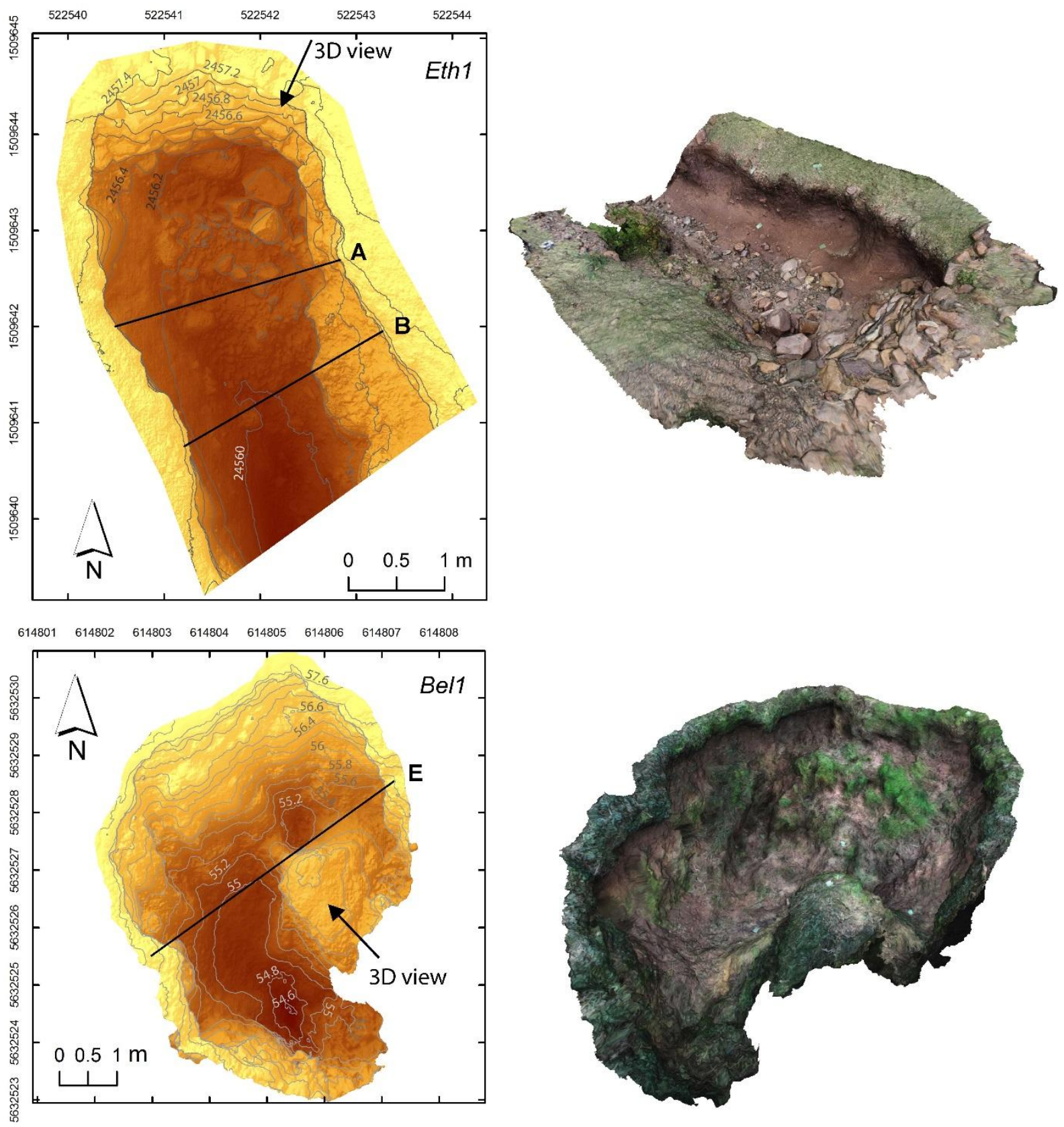

288 Figure 5: Examples of 2.5D DEMs of gullies Eth1 and Bel1 (left) and the respective draped 3D 289 photomodels (from an oblique viewpoint). Cross-sectional profiles are given in Fig. 6. 
CITE AS Frankl, A., Stal, C., Abraha, A., Nyssen, J., Rieke-Zapp, D., De Wulf, A., Poesen, J., 2015. Detailed recording of gully morphology in 3D through image-based modelling. Catena 127, 92-101.

290 Coordinates are in UTM-WGS1984.

292 Considering the gully cross-sectional profiles, a comparison was made between the cross293 sections as measured in the field to those derived from the $2.5 \mathrm{D}$ and $3 \mathrm{D}$ models. Simple 294 approximation of cross-sections in the field by equation 1 can yield relatively good results, with 295 differences of $<1 \%$ up to $14 \%$ when compared to the cross-sections computed from the image296 based 3D models (Table 2). However, to understand gully erosion dynamics, the cross-sections 297 derived from the image-based 3D models are much more informative. From the cross-sections 298 alone, we can derive that gully head Eth1 is more erosive than Eth2, the former having steep 299 undercut walls and the latter having smooth and gently sloping walls (Fig. 6A-F). Moreover, a 300 stabilization level can be observed on the gully floor of Eth1, corresponding to a previous 301 equilibrium status (Fig. 6B). Similar observations can be made on the cross-sections of gullies 302 Bel1 and Bel2. Both have undercut walls, which on cross-section E connects to a soil pipe (Fig. 303 6E). A comparison of the cross-sectional areas computed from the 2.5D models with the 3D 304 models shows that the former slightly underestimate (up to $2.5 \%$ ) the gully cross-sectional area, 305 as the 2.5D models not include the undercut gully walls (Table 2).

Table 2: Gully cross-sections and volumes.

\begin{tabular}{ccccccc}
\hline \multirow{2}{*}{ Gully } & \multicolumn{3}{c}{ Cross-sectional area $\left(\mathbf{m}^{\mathbf{2}}\right)$} & \multicolumn{2}{c}{ Difference \% } \\
& $\begin{array}{c}\text { Cross- } \\
\text { section }\end{array}$ & $\begin{array}{c}\text { Tape } \\
\text { meter }\end{array}$ & Model & Model & Field- & M2.5D- \\
\hline Eth1 & A & 2.33 & 2.24 & 2.29 & 1.7 & -2.2 \\
Eth1 & B & 2.91 & 2.61 & 2.68 & 8.6 & -2.6 \\
Eth2 & C & 0.99 & 1.01 & 1.01 & -2.0 & 0
\end{tabular}


CITE AS Frankl, A., Stal, C., Abraha, A., Nyssen, J., Rieke-Zapp, D., De Wulf, A., Poesen, J., 2015. Detailed recording of gully morphology in 3D through image-based modelling. Catena 127, $92-101$.

\begin{tabular}{|c|c|c|c|c|c|c|}
\hline Eth2 & D & 0.81 & 0.71 & 0.71 & 14.1 & 0 \\
\hline Bel1 & $E$ & 8.56 & 8.33 & 8.54 & 0.2 & -2.5 \\
\hline Bel2 & $\mathrm{F}$ & 7.51 & 7.06 & 7.11 & 5.6 & -0.7 \\
\hline & \multicolumn{2}{|c|}{ Volume $\left(\mathrm{m}^{3}\right)$} & \multicolumn{2}{|c|}{ Difference } & & \\
\hline Gully & $\begin{array}{c}\text { Model } \\
2.5 \mathrm{D}\end{array}$ & $\begin{array}{c}\text { Model } \\
\text { 3D }\end{array}$ & $\begin{array}{c}\text { M2.5D- } \\
\text { M3D } \\
(\%)\end{array}$ & $\begin{array}{c}\text { M2.5D- } \\
\text { M3D } \\
\left(\mathrm{m}^{3}\right)\end{array}$ & & \\
\hline Bel1 & 29.08 & 29.27 & -0.65 & -0.19 & & \\
\hline Bel2 & 18.99 & 19.26 & -1.4 & -0.27 & & \\
\hline Eth1 & 18.12 & 18.18 & -0.33 & -0.06 & & \\
\hline Eth2 & 2.17 & 2.17 & 0 & 0 & & \\
\hline
\end{tabular}


CITE AS Frankl, A., Stal, C., Abraha, A., Nyssen, J., Rieke-Zapp, D., De Wulf, A., Poesen, J., 2015. Detailed recording of gully morphology in 3D through image-based modelling. Catena 127, 92-101.
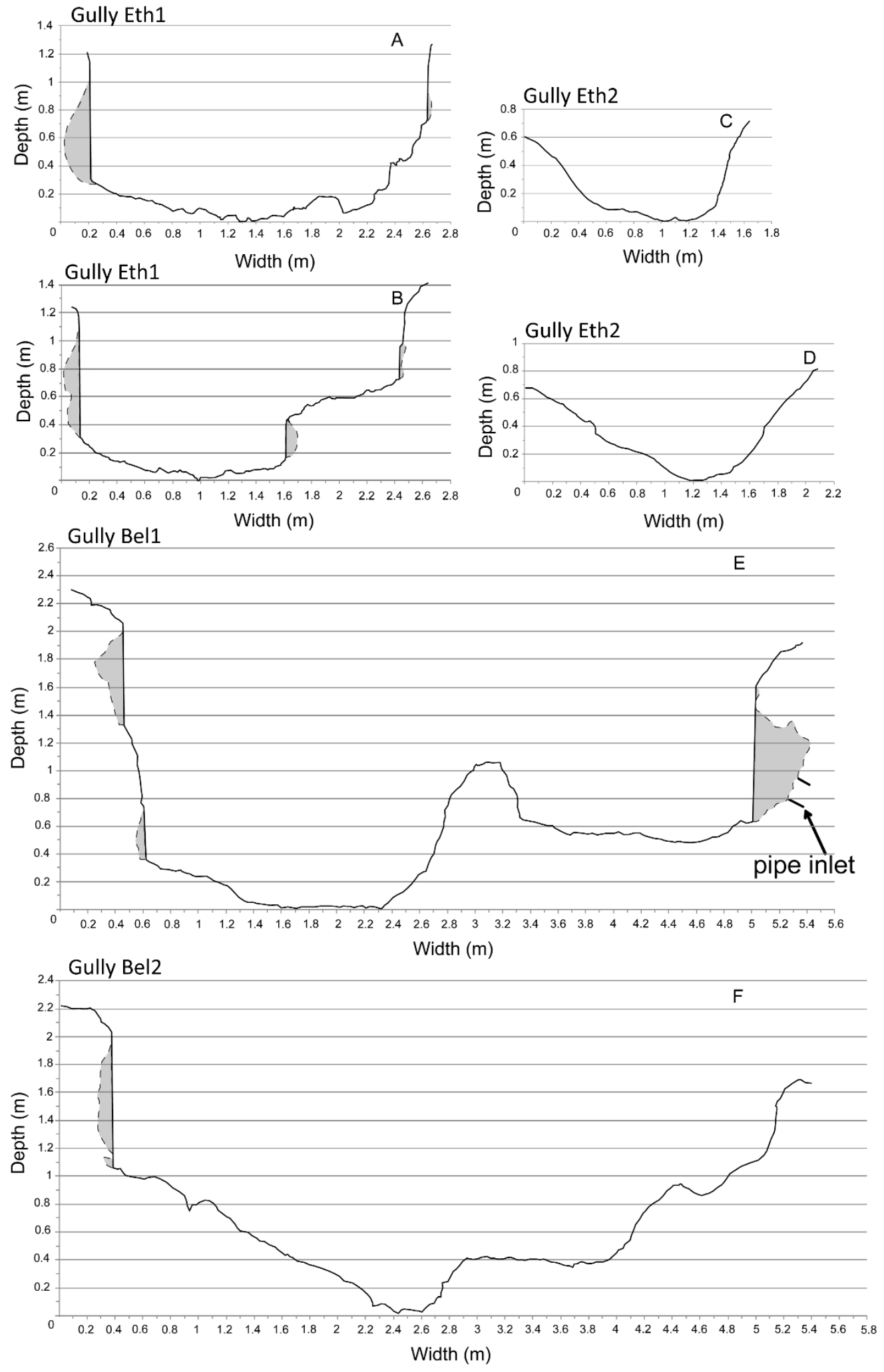
CITE AS Frankl, A., Stal, C., Abraha, A., Nyssen, J., Rieke-Zapp, D., De Wulf, A., Poesen, J., 2015. Detailed recording of gully morphology in 3D through image-based modelling. Catena 127, 92-101.

Figure 6: The cross-sectional profiles derived from $2.5 \mathrm{D}$ models show vertical walls when

310 undercutting occurs (black lines). These undercut gully walls (grey fill on cross-section) do occur 311 on the 3D models prepared from image-based 3D modelling. All sections are at the same scale 312 and with no vertical exaggeration.

314 The gully volume calculations in $2.5 \mathrm{D}$ and $3 \mathrm{D}$ are given in Table 2, and the differences between 315 the two model types range between 0 and $0.27 \mathrm{~m}^{3}$. Although these values are rather small, 316 especially compared with the total volume of the headcuts, these values represent the volume of 317 the undercuts and pipe inlets, and thus, are indicators of the erosive activity of the gully. The 318 incised Bel2 and Bel2 Filled models were combined in Fig. 7 and thus represent the volume of soil 319 that was used by the farmer to fill the gully.

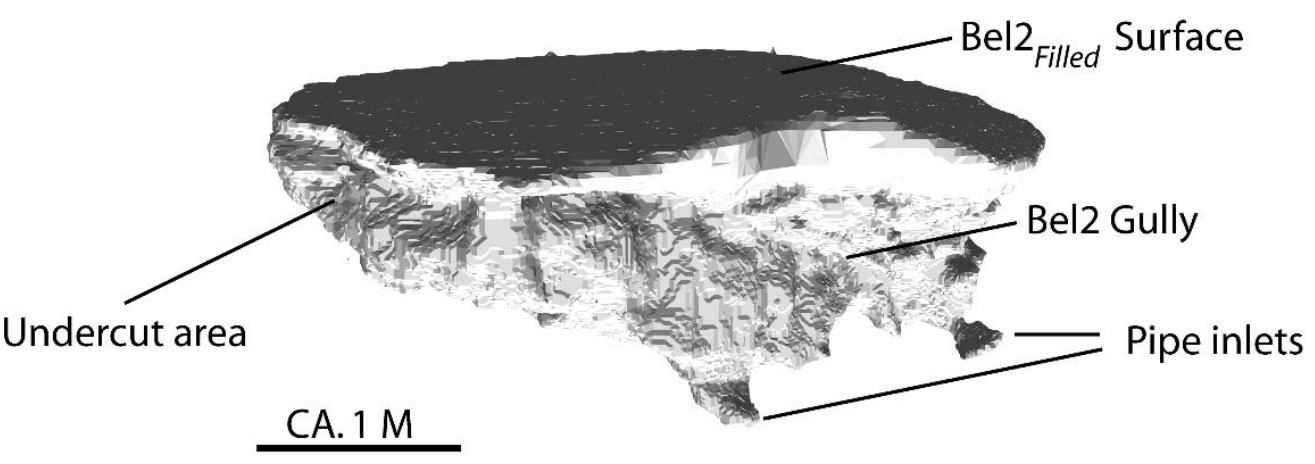

322 Figure 7: Merged Bel2 and Bel2 $2_{\text {Filled }}$ models for 3D volume calculation showing pipe inlets and 323 undercut gully walls. 
CITE AS Frankl, A., Stal, C., Abraha, A., Nyssen, J., Rieke-Zapp, D., De Wulf, A., Poesen, J., 2015. Detailed recording of gully morphology in 3D through image-based modelling. Catena 127, 92-101.

\section{4. Discussion: Application of image-based 3D modelling in earth sciences}

326 Photo cameras are fairly easy to use and to transport, and therefore, photogrammetric approaches

327 for studying geomorphological processes in the field have been applied since more than 30 years

328 (Welch et al., 1984; Chandler, 1999). Initially, terrestrial photographs were processed in a similar

329 way to aerial photographs, by respecting the schematic block configuration of data acquisition

330 from a vertical perspective. Practically, this was often achieved by mounting one or multiple

331 cameras on a horizontal bar at ca. 2-3 m above the soil surface (Brasington and Smart, 2003).

332 Accuracies provided by these methods proved to be at millimeter level (Rieke-Zapp and Nearing,

333 2005; Carbonneau et al., 2003). Methodologies and setup of close-range photogrammetric

334 methodologies however often remained complex, time-consuming and expensive (although more

335 cost- and user-friendly methods were also proposed;, Carbonneau et al., 2003) .

336 Image-based modelling allows to produce accurate 3D models from multiple photographs, in a

337 more flexible, versatile and user-friendly way. As data collection is straightforward and not 338 complex, image-based modelling is rapidly gaining interest of earth scientists, who apply the 339 method at various spatial scales from centimeter to kilometre level. Examples include small rock 340 fragments, stream beds, lava flows, coastal cliffs, moraines, bedrock ridges and volcanic domes

341 (Diefenbach et al., 2012; James and Robson, 2012; Westoby et al., 2012; Bouratsis et al., 2013).

342 Degrees of accuracy are related to the distance between the photographer and the surveyed 343 landform, and is thus dependent on the scale of the latter. In the reported examples, meter to 344 decimeter-level accuracies were achieved for large landforms photographed from air planes or 345 nearby mountain slope (e.g. moraines), while an accuracy at millimetre-level could be achieved 
CITE AS Frankl, A., Stal, C., Abraha, A., Nyssen, J., Rieke-Zapp, D., De Wulf, A., Poesen, J., 2015. Detailed recording of gully morphology in 3D through image-based modelling. Catena 127, 92-101.

346 for small objects photographed in a laboratory (rock fragment). This means that, for large 347 landforms, the SfM-MVS approach yields accuracies which are similar to those provided by 348 large-scale aerial photographs, while for smaller features, the method is equivalent to terrain 349 modelling by (terrestrial) LiDAR or laser scanning. As indicated by Diefenbach et al. (2012), 350 image-based 3D modelling allows to monitor closely landforms and landscapes at good spatial 351 resolution and at time-intervals appropriate to the study.

352 For monitoring gully erosion, this study demonstrates that detailed information on gully 353 morphology and volume can be obtained by the use of $3 \mathrm{D}$ photomodelling. Novel is that the 354 quantification of gully morphologies is based on the actual 3D morphology, and not on a 355 simplified one that does not include undercut gully walls or pipe inlets. Taking into account the 356 latter is, however, important for assessing the dynamics of the gully and for detailed 357 understanding of gully morphology and processes involved. Gullies which are eroding basically 358 develop through widening and deepening of the channel or by the upslope advance of the 359 headcut (Knighton, 1998). By producing time-series of DEMs erosion rates can be computed, 360 yielding detailed information on the morphologic changes occurring, and thus, on the gully 361 development processes involved. This has already been demonstrated from 2.5D approaches 362 (D'Oleire-Oltmanns et al., 2012). The main disadvantage here is, however, that the gully needs 363 to be surveyed over a certain period of time before erosional dynamics can be defined (usually 364 over a rainfall season that accounts for most of the geomorphic change). DEMs produced in a 3D 365 environment can partially add to such interpretations, as they allow to predict much of the 366 change that will occur over time from a single survey. Overhanging walls and soil pipes are 
CITE AS Frankl, A., Stal, C., Abraha, A., Nyssen, J., Rieke-Zapp, D., De Wulf, A., Poesen, J., 2015. Detailed recording of gully morphology in 3D through image-based modelling. Catena 127, 92-101.

367 geomophologically very unstable an cannot stabilize as such. Mapping the zones in a gully 368 where overhanging walls and piping occurs (by subtracting a 3D model with a 2.5D version of it) 369 therefore yields much information on the gully erosion dynamics which occur, and thus also on 370 the erosion rates to expect. This is especially true for gullies that have accomplished most of their 371 bed degradation and mainly develop through widening. Next to this study, research on the use of 372 SfM-MVS methodologies in gully erosion studies is rapidly increasing, with examples in both 373 2.5D and 3D environments (Castillo et al., 2012; D’Oleire-Oltmanns et al., 2012; Kluibenschädl 374 et al., 2013; Kaiser et al., 2014).

375 Scanned analogue photographs can also be used in the SfM-MVS methodology, if the metadata 376 normally included in the EXIF-files attached to digital photography are available. Metadata 377 requirements are the focal length, focal point, pixels in $\mathrm{X}$ and $\mathrm{Y}$ (determines the crop factor) and 378 the pixel size. In the absence of these data, PhotoScan might still be able to create a sparse point 379 cloud, although accuracies are expected to be low (see Agisoft manual at 380 http//:downloads.agisoft.ru). Thus, historical photographs taken from different positions over the 381 same scene can also be used to create 3D models of surface morphologies. Extensive datasets of 382 historical photographs are often available, especially along historical tracks or when considering 383 scenic landscapes (Nyssen et al., 2010). Several studies have demonstrated the value of such 384 datasets in studying landscape features (including gullies) in a semi-quantitative way (e.g. Frankl 385 et al., 2011; Nyssen et al., 2013), and thus image-based 3D modelling offers a new tool to better 386 understand past geomorphic process rates. 
CITE AS Frankl, A., Stal, C., Abraha, A., Nyssen, J., Rieke-Zapp, D., De Wulf, A., Poesen, J., 2015. Detailed recording of gully morphology in 3D through image-based modelling. Catena 127, 92-101.

\section{Conclusions}

389 Image-based 3D modelling of gullies is a rather innovative method that allows to rapidly obtain 390 accurate (mm to cm-level) data on gully morphologies and dynamics. Data acquisition is fairly 391 easy and does not require specific equipment besides a photo camera, PhotoScan software (or 392 other existing softwares) and a computer laboratory. The production of 3D models is based on a 393 Structure from Motion-Multi View Stereo (SfM-MVS) workflow. As data-acquisition from the 394 ground perspective allows the integration of undercut gully walls and pipe inlets, image-based 395 modelling provides a tool to quantify the actual 3D morphology of gullies. With that, gully 396 erosion dynamics can be better understood as unstable areas can be detected. This contrasts with 397 approaches using 2.5D models, as can be obtained by aerial photography. For the latter, the gully 398 morphology is simplified due to the limitation of having only one $\mathrm{z}$ coordinate per xy set. The 399 flexibility of the method makes it applicable in different environments for which other 400 acquisition methods (e.g., Terrestrial Laser Scanning) are not available, and is suitable when high 401 temporal resolutions are needed in monitoring projects.

\section{Acknowledgements}

404 This research was partially funded with a VLIR-UOS (K219012N) travel grant of Amaury 405 Frankl (Flanders, Belgium). Thanks are also expressed to Gebrekidan Mesfin for field assistance 406 and to the VLIR-UOS team at Mekelle University for logistical support.

\section{References}


CITE AS Frankl, A., Stal, C., Abraha, A., Nyssen, J., Rieke-Zapp, D., De Wulf, A., Poesen, J., 2015. Detailed recording of gully morphology in 3D through image-based modelling. Catena 127, $92-101$.

AGIV, 2008. Uitvoeren van GPS-metingen met behulp van Flemish Positioning Service (FLEPOS). www.agiv.be/flepos, 34.

Alexandre, J., Erpicum, M., Mabille, G., Cornet, Y., 1998. Précipitations atmosphériques et altitude. Prélude à une cartographie des montants annuel et mensuels en Belgique Publications de l'Association Internationale de Climatologie. 11, 219-226.

Bouratsis, P., Diplas, P., Dancey, C.L., Apsilidis, N., 2013. High-resolution 3-D monitoring of evolving sediment beds. Water Resources Research. 49(2), 977-992.

Brasington, J., Smart, R.M.A., 2003. Close range digital photogrammetric analysis of experimental drainage basin evolution. Earth Surface Processes and Landforms. 28(3), 231-247.

Carbonneau, P.E., Lane, S.N., Bergeron, N.E., 2003. Cost-effective non-metric close-range digital photogrammetry and its application to a study of coarse gravel river beds. International Journal of Remote Sensing. 24(14), 2837-2854.

Castillo, C., Pérez, R., James, M.R., Quinton, J.N., Taguas, E.V., Gómez, J.A., 2012. Comparing the Accuracy of Several Field Methods for Measuring Gully Erosion. Soil Science Society of America Journal. 76(4), 1319-1332.

Chandler, J., 1999. Effective application of automated digital photogrammetry for geomorphological research. Earth Surface Processes and Landforms. 24(1), 51-63.

Clarke, M.A., Walsh, R.P.D., 2006. Long-term erosion and surface roughness change of rain429 forest terrain following selective logging, Danum Valley, Sabah, Malaysia. Catena. 68(23), 109-123. 
CITE AS Frankl, A., Stal, C., Abraha, A., Nyssen, J., Rieke-Zapp, D., De Wulf, A., Poesen, J., 2015. Detailed recording of gully morphology in 3D through image-based modelling. Catena 127, $92-101$.

430 Corbane, C., Raclot, D., Jacob, F., Albergel, J., Andrieux, P., 2008. Remote sensing of soil surface characteristics from a multiscale classification approach. Catena. 75(3), 308-318.

Diefenbach, A.K., Crider, J.G., Schilling, S.P., Dzurisin, D., 2012. Rapid, low-cost photogrammetry to monitor volcanic eruptions: an example from Mount St. Helens, Washington, USA. Bulletin of Volcanology. 74(2), 579-587.

D’Oleire-Oltmanns, S., Marzolff, I., Peter, K., Ries, J., 2012. Unmanned Aerial Vehicle (UAV)

Frankl, A., Nyssen, J., De Dapper, M., Mitiku Haile, Billi, P., Munro, R.N., Deckers, J., Poesen, J., 2011. Linking long-term gully and river channel dynamics to environmental change

Frankl, A., Poesen, J., Deckers, J., Haile, M., Nyssen, J., 2012. Gully head retreat rates in the using repeat photography (North Ethiopia). Geomorphology. 129(3-4), 238-251. semi-arid highlands of Northern Ethiopia. Geomorphology. 173-174(0), 185-195.

Giménez, R., Marzolff, I., Campo, M.A., Seeger, M., Ries, J.B., Casalí, J., Álvarez-Mozos, J., 2009. Accuracy of high-resolution photogrammetric measurements of gullies with contrasting morphology. Earth Surface Processes and Landforms. 34(14), 1915-1926.

Gómez-Gutiérrez, Á., Schnabel, S., Berenguer-Sempere, F., Lavado-Contador, F., RubioDelgado, J., 2014. Using 3D photo-reconstruction methods to estimate gully headcut erosion. Catena. 120, 91-101. of stereoscopic images taken from a microdrone for the documentation of heritage - An example from the Tuekta burial mounds in the Russian Altay. Journal of Archaeological 
CITE AS Frankl, A., Stal, C., Abraha, A., Nyssen, J., Rieke-Zapp, D., De Wulf, A., Poesen, J., 2015. Detailed recording of gully morphology in 3D through image-based modelling. Catena 127, 92-101.

Science. 38(11), 2968-2978.

452 453

Heritage, G., Hetherington, D., 2007. Towards a protocol for laser scanning in fluvial geomorphology. Earth Surface Processes and Landforms. 32(1), 66-74.

Hülksen, F., Eckes, C., Kuck, R., Unterberg, J., Jörg, S., 2007. Modeling and animating virtual humans for real-time applications. International Journal of Virtual Reality. 6(4), 11-20.

Jacob, M., Frankl, A., Mitiku, H., Zwertvaegher, A., Nyssen, J., 2013. Assessing spatio-temporal rainfall variability in a tropical mountain area (Ethiopia) using NOAA's rainfall estimates, International Journal of Remote Sensing. 34(23), 8305-8321.

James, M.R., Robson, S., 2012. Straightforward reconstruction of 3D surfaces and topography with a camera: Accuracy and geoscience application. Journal of Geophysical ResearchEarth Surface. 117, 1-17.

Javernick, L., Brasington, J., Caruso, B., 2014. Modeling the topography of shallow braided rivers using Structure-from-Motion photogrammetry. Geomorphology. 213, 166-182.

Kaiser, A., Neugirg, F., Rock, G., Müller, C., Haas, F., Ries, J., Schmidt, J., 2014. Small-Scale Surface Reconstruction and Volume Calculation of Soil Erosion in Complex Moroccan Gully Morphology Using Structure from Motion. Remote Sensing. 6, 7050-7080.

Kluibenschädl, F., Strohmeier, S., Klik, A., 2013. Assessment of gully erosion by linking photogrammetric methods and field measurements, EGU Geophysical Research Abstracts 5557-4.

Knighton, D., 1998. Fluvial forms and processes - a new perspective. Hodder Education, London. Lourakis, M., Argyros, A., 2009. SBA: A software package for generic sparse bundle adjustment. 
CITE AS Frankl, A., Stal, C., Abraha, A., Nyssen, J., Rieke-Zapp, D., De Wulf, A., Poesen, J., 2015. Detailed recording of gully morphology in 3D through image-based modelling. Catena 127, $92-101$. ACM Transactions on Mathematical Software. 36(1), 1-30.

473 474 475

Lucieer, A., de Jong, S., Turner, D., 2013. Mapping landslide displacements using Structure from Motion (SfM) and image correlation of multi-temporal UAV photography. Progress in Physical Geography. DOI: 10.1177/0309133313515293.

Marzolff, I. \& Poesen, J. 2009. The potential of 3D gully monitoring with GIS using highresolution aerial photography and a digital photogrammetry system. Geomorphology 111:48-60.

Merla, G., Abbate, E., Azzaroli, A., Bruni, P., Canuti, P., Fazzuoli, M., Sagri, M., Tacconi, P., 1979. A geological map of Ethiopia and Somalia (1973) 1:2.000.000 and comment. University of Florence, Firenze, Italy.

Montanarella, L., Vargas, R., 2012. Global governance of soil resources as a necessary condition for sustainable development. Current Opinion in Environmental Sustainability. 4(5), 559564.

Nyssen, J., den Branden, J.V., Spalević, V., Frankl, A., Van de velde, L., Čurović, M., Billi, P., 2013. Twentieth century land resilience in Montenegro and consequent hydrological response. Land Degradation \& Development. online early view.

Nyssen, J., Frankl, A., Munro, R.N., Billi, P., Mitiku Haile, 2010. Digital Photographic Archives for Environmental and Historical Studies: An Example from Ethiopia. Scottish Geographical Journal. 126(3). 185 - 207.

Nyssen, J., Naudts, J., De Geyndt, K., Mitiku Haile, Poesen, J., Moeyersons, J., Deckers, J., 2008. Soils and land use in the Tigray highlands (Northern Ethiopia). Land Degradation \& 
CITE AS Frankl, A., Stal, C., Abraha, A., Nyssen, J., Rieke-Zapp, D., De Wulf, A., Poesen, J., 2015. Detailed recording of gully morphology in 3D through image-based modelling. Catena 127, $92-101$.

Development. 19(3). 257-274.

494 Peel, M.C., Finlayson, B.L., McMahon, T.A., 2007. Updated world map of the Koppen-Geiger climate classification. Hydrology and Earth System Sciences. 11(5), 1633-1644.

Perroy, R.L., Bookhagen, B., Asner, G.P., Chadwick, O.A., 2010. Comparison of gully erosion estimates using airborne and ground-based LiDAR on Santa Cruz Island, California. Geomorphology. 118(3-4), 288-300.

Perroy, R.L., Bookhagen, B., Chadwick, O.A., Howarth, J.T., 2012. Holocene and Anthropocene Landscape Change: Arroyo Formation on Santa Cruz Island, California. Annals of the Association of American Geographers. 102(6), 1229-1250.

Peter, D.K., d'Oleire-Oltmanns, S., Ries, J.B., Marzolff, I., Ait Hssaine, A., 2014. Soil erosion in gully catchments affected by land-levelling measures in the Souss Basin, Morocco, analysed by rainfall simulation and UAV remote sensing data. Catena, 113, 24-40.

Pfeifer, N., 2002. 3D Terrain models on the basis of a triangulation. Geowissenschaftlichte mitteilungen, 65. Institut für Photogrammetie und Fernkundung, Vienna, Austria.

Poesen, J., Govers, G., 1990. Gully erosion in the loam belt of Belgium : typology and control measures. In: Boardman, J., Foster, D, Dearing, J. (Eds.), Soil Erosion on Agricultural Land. Wiley, Chichester, U.K., 513-530.

Poesen, J., Nachtergaele, J., Verstraeten, G., Valentin, C., 2003. Gully erosion and environmental change: importance and research needs. Catena. 50(2-4), 91-133. production in cultivated lands and rangelands. IAHS Publ. 236:251-266. 
CITE AS Frankl, A., Stal, C., Abraha, A., Nyssen, J., Rieke-Zapp, D., De Wulf, A., Poesen, J., 2015. Detailed recording of gully morphology in 3D through image-based modelling. Catena 127, $92-101$.

514 Pollefeys, M., Koch, R., Vergauwen, M., Van Gool, L., 2000. Automated reconstruction of 3D scenes from sequences of images. ISPRS Journal of Photogrammetry and Remote Sensing. 55(4). 251-267.

Remondino, F., El-Hakim, S., 2006. Image-based 3D Modelling: A Review. The Photogrammetric Record. 21(115), 269-291.

Rieke-Zapp, D.H., Nearing, M.A., 2005. Digital close range photogrammetry for measurement of soil erosion. The Photogrammetric Record, 20(109), 69-87.

Ries, J.B., Marzolff, I., 2003. Monitoring of gully erosion in the Central Ebro Basin by largescale aerial photography taken from a remotely controlled blimp. Catena. 50(2-4), 309328.

Robertson, D., Cipolla, R., 2009. Structure from motion. In: Varga, M. (Ed.), Practical image processing and computer vision. John Wiley, Hoboken, NJ, USA., 49.

Schumm, S.A., 2005. River variability and complexity. Cambridge University Press, New York.

Seitz, S., Curless, B., Diebel, J., Scharstein, D., Szeliski, R., 2006. A comparison and evaluation of multi-view stereo reconstruction algorithms, IEEE Computer Society Conference on Computer Vision and Pattern Recognition, New York, NY, USA, 17-22 June, 519-528.

Stal, C., De Wulf, A., De Coene, K., De Maeyer, P., Nuttens, T., Ongena, T., 2012. Digital

533 Stal, C., De Wulf, A., Nuttens, T., De Maeyer, P., Goossens, R., 2011. Reconstruction of a 534 medieval wall: photogammetric mapping and quality analysis by terrestrial laser scanning. 
CITE AS Frankl, A., Stal, C., Abraha, A., Nyssen, J., Rieke-Zapp, D., De Wulf, A., Poesen, J., 2015. Detailed recording of gully morphology in 3D through image-based modelling. Catena 127, 92-101.

31th EARSeL symposium : Remote sensing and geoinformation not only for scientific cooperation, Prague, Czech Republic, 54-65.

Valentin, C., Poesen, J., Li, Y., 2005. Gully erosion: Impacts, factors and control. Catena. 63(2-3), 132-153.

Vanwalleghem, T., Poesen, J., Nachtergaele, J., Verstraeten, G., 2005. Characteristics, controlling factors and importance of deep gullies under cropland on loess-derived soils. Geomorphology. 69(1-4), 76-91.

Verhoeven, G., Doneus, M., Briese, C., Vermeulen, F., 2012. Mapping by matching: a computer vision-based approach to fast and accurate georeferencing of archaeological aerial photographs. Journal of Archaeological Science. 39(7), 2060-2070.

Welch, R., Jordan, T., Thomas, A.W., 1984. A photogrammetric technique for measuring soil erosion. Journal of Soil and Water Conservation. 39(3), 191-194.

Westoby, M.J., Brasington, J., Glasser, N.F., Hambrey, M.J., Reynolds, J.M., 2012. "Structurefrom-Motion" photogrammetry: A low-cost, effective tool for geoscience applications. Geomorphology. 179(0), 300-314. 